\title{
Permanent pacemaker implantation is never a benign complication after aortic valve replacement
}

\author{
Suk Ho Sohn, Ho Young Hwang \\ Department of Thoracic and Cardiovascular Surgery, Seoul National University Hospital, Seoul National University College of Medicine, Seoul, \\ Korea \\ Correspondence to: Ho Young Hwang, MD, PhD. Department of Thoracic and Cardiovascular Surgery, Seoul National University Hospital, Seoul \\ National University College of Medicine, 101 Daehak-ro, Jongno-gu, Seoul 03080, Korea. Email: scalpel@hanmail.net. \\ Provenance: This is an invited Editorial commissioned by Executive Editor-in-Chief Jianxing He (Director of the Thoracic Surgery Department, The \\ First Affiliated Hospital of Guangzhou Medical University, Guangzhou, China). \\ Comment on: Mehaffey JH, Haywood NS, Hawkins RB, et al. Need for Permanent Pacemaker After Surgical Aortic Valve Replacement Reduces \\ Long-Term Survival. Ann Thorac Surg 2018;106:460-5.
}

Submitted Aug 22, 2018. Accepted for publication Sep 19, 2018.

doi: $10.21037 /$ jtd.2018.09.107

View this article at: http://dx.doi.org/10.21037/jtd.2018.09.107

Since the first report of an in-man transcatheter aortic valve replacement (TAVR) in 2002 by Cribier et al. (1), its role in the management of severe aortic stenosis (AS) has grown rapidly. Recent interest in minimally invasive approaches, driven not only by cardiac surgeons and cardiologists but also by patients, has facilitated the widespread use of TAVR; its indications have now expanded to include intermediate-risk and even low-risk surgical patient groups (2-4). Numerous randomized controlled trials (RCTs) have been performed or are still on-going; most studies demonstrated that there were no significant differences in all-cause mortality in patients with high or intermediate surgical risk (2,5-7). One RCT even showed a significantly lower mortality rate in the TAVR group than in the surgical AVR (SAVR) group at 1 year after AVR (14.2\% vs. 19.1\%, $\mathrm{P}=0.04)$ (8).

However, procedural drawbacks of these 'minimally invasive' aortic valve procedures include higher risks of paravalvular leak and atrioventricular block requiring permanent pacemaker implantation (PPI) after procedures. Both balloon-expandable and self-expanding valves pose greater risks of PPI than does SAVR because of increased mechanical interaction between the devices and the conduction system generated by radial force (9). The incidence of PPI after TAVR varies among studies from $2 \%$ to $50 \%$ (10). Despite recent development of newergeneration devices and increased practitioner awareness of this serious complication, the incidence of PPI after procedures remains over $10 \%$ (9). Previous studies demonstrated conflicting results regarding the impact of PPI on mid-term outcomes after TAVR. A recent study showed a significantly increased hazard of 1-year all-cause mortality after PPI in TAVR patients (11). Another study insisted that PPI was just a benign complication that did not affect outcomes and was even a protective factor against the occurrence of unexpected death (12).

The negative impact of PPI on long-term clinical outcomes after SAVR or TAVR has several explanations (13-15): (I) ineffective mechanical work due to asynchronous activation of ventricular segments; (II) resultant regional hypo-perfusion in the septal area and progressive ventricular remodeling; (III) reduced cardiac output owing to atrioventricular dyssynchrony; (IV) late occurrence of mitral regurgitation induced by right ventricular pacing; and (V) infectious complications such as pocket site infection and lead infection.

In this recent study by Mehaffey and his colleagues (16), the authors raised this important issue once again. Because long-term data after TAVR are lacking, this study aimed to evaluate the detrimental impact of PPI on the longterm clinical outcomes in SAVR patients that could be extrapolated to the TAVR population. Their excellent results of overall PPI rate after SAVR of $2.7 \%$ should be congratulated. The authors showed that the PPI was 
associated with a $50 \%$ increase in long-term all-cause mortality. Main strengths of their study include the followings: (I) the authors included a sufficient sample size of 2,600 patients over a 15-year study period and (II) a median follow-up duration of 7.5 years is long enough to clearly elucidate long-term effects of PPI. There is nevertheless a caveat in this study; preoperative risk factors that could affect long-term all-cause mortality were adjusted in their multivariable analysis only by patient STS score. Therefore, there remains a possibility that their main findings were affected by confounding variables. Despite this issue, this study delivers a clear message: "Permanent pacemaker implantation after TAVR is not at all a benign complication".

\section{Acknowledgements}

None.

\section{Footnote}

Conflicts of Interest: The authors have no conflicts of interest to declare.

\section{References}

1. Cribier A, Eltchaninoff H, Bash A, et al. Percutaneous transcatheter implantation of an aortic valve prosthesis for calcific aortic stenosis: first human case description. Circulation. 2002;106:3006-8.

2. Leon MB, Smith CR, Mack MJ, et al. Transcatheter or Surgical Aortic-Valve Replacement in Intermediate-Risk Patients. N Engl J Med 2016;374:1609-20.

3. Cribier A, Durand E, Eltchaninoff H. Patient selection for TAVI in 2014: is it justified to treat low- or intermediaterisk patients? The cardiologist's view. EuroIntervention 2014;10 Suppl U:U16-21.

4. Nishimura RA, Otto CM, Bonow RO, et al 2017 AHA/ ACC Focused Update of the 2014 AHA/ACC Guideline for the Management of Patients With Valvular Heart Disease: A Report of the American College of Cardiology/ American Heart Association Task Force on Clinical Practice Guidelines. Circulation 2017;135:e1159-95.

5. Smith CR, Leon MB, Mack MJ, et al. Transcatheter versus surgical aortic-valve replacement in high-risk patients. $\mathrm{N}$ Engl J Med 2011;364:2187-98.

6. Nielsen HH, Klaaborg KE, Nissen H, et al. A prospective, randomised trial of transapical transcatheter aortic valve implantation vs. surgical aortic valve replacement in operable elderly patients with aortic stenosis: the STACCATO trial. EuroIntervention 2012;8:383-9.

7. Thyregod HG, Steinbrüchel DA, Ihlemann N, et al. Transcatheter Versus Surgical Aortic Valve Replacement in Patients With Severe Aortic Valve Stenosis: 1-Year Results From the All-Comers NOTION Randomized Clinical Trial. J Am Coll Cardiol 2015;65:2184-94.

8. Adams DH, Popma JJ, Reardon MJ, et al. Transcatheter aortic-valve replacement with a self-expanding prosthesis. N Engl J Med 2014;370:1790-8.

9. Auffret V, Puri R, Urena M, et al. Conduction Disturbances After Transcatheter Aortic Valve Replacement: Current Status and Future Perspectives. Circulation 2017;136:1049-69.

10. Siontis GC, Jüni P, Pilgrim T, et al. Predictors of permanent pacemaker implantation in patients with severe aortic stenosis undergoing TAVR: a meta-analysis. J Am Coll Cardiol 2014;64:129-40.

11. Fadahunsi OO, Olowoyeye A, Ukaigwe A, et al. Incidence, Predictors, and Outcomes of Permanent Pacemaker Implantation Following Transcatheter Aortic Valve Replacement: Analysis From the U.S. Society of Thoracic Surgeons/American College of Cardiology TVT Registry. JACC Cardiovasc Interv 2016;9:2189-99.

12. Urena M, Webb JG, Tamburino C, et al. Permanent pacemaker implantation after transcatheter aortic valve implantation: impact on late clinical outcomes and left ventricular function. Circulation 2014;129:1233-43.

13. Vernooy K, Verbeek XA, Peschar M, et al. Left bundle branch block induces ventricular remodelling and functional septal hypoperfusion. Eur Heart J 2005;26:91-8.

14. Catanzariti D, Maines M, Manica A, et al. Permanent Hisbundle pacing maintains long-term ventricular synchrony and left ventricular performance, unlike conventional right ventricular apical pacing. Europace 2013;15:546-53.

15. Barold SS, Ovsyshcher IE. Pacemaker-induced mitral regurgitation. Pacing Clin Electrophysiol 2005;28:357-60.

16. Mehaffey JH, Haywood NS, Hawkins RB, et al. Need for Permanent Pacemaker After Surgical Aortic Valve Replacement Reduces Long-Term Survival. Ann Thorac Surg 2018;106:460-5.

Cite this article as: Sohn SH, Hwang HY. Permanent pacemaker implantation is never a benign complication after aortic valve replacement. J Thorac Dis 2018;10(Suppl 33):S4080-S4081. doi: 10.21037/jtd.2018.09.107 